\title{
Different signalling pathways contribute to the control of GPD1 gene expression by osmotic stress in Saccharomyces cerevisiae
}

\author{
Martijn Rep, ${ }^{1}$ Jacobus Albertyn, ${ }^{2}$ Johan M. Thevelein, ${ }^{1}$ Bernard A. Prior ${ }^{2} \dagger$ \\ and Stefan Hohmann ${ }^{1,3}$
}

Author for correspondence: Stefan Hohmann. Tel: +46 31773 2595. Fax: +46 317732599. e-mail: hohmann@gmm.gu.se

\footnotetext{
1 Laboratorium voor Moleculaire Celbiologie, Katholieke Universiteit Leuven, Kardinaal Mercierlaan 92, B-3001 Heverlee, Flanders, Belgium

2 Department of Microbiology and Biochemistry, University of the Orange Free State, PO Box 339, Bloemfontein 9300 , South Africa

3 Department of Cell and Molecular Biology/Microbiology, Goteborg University, Box 462, SE-405 30 Göteborg, Sweden
}

\begin{abstract}
Yeast cells respond to a shift to higher osmolarity by increasing the cellular content of the osmolyte glycerol. This response is accompanied by a stimulation of the expression of genes encoding enzymes in the glycerol production pathway. In this study the osmotic induction of one of those genes, GPD1, which encodes glycerol-3-phosphate dehydrogenase, was monitored in time course experiments. The response is independent of the osmolyte and consists of four apparent phases: a lag phase, an initial induction phase, a feedback phase and a sustained long-term induction. Osmotic shock with progressively higher osmolyte concentrations caused a prolonged lag phase. Deletion of HOG1, which encodes the terminal protein kinase of the high osmolarity glycerol (HOG) response pathway, led to an even longer lag phase and drastically lower basal and induced GPD1 mRNA levels. However, the induction was only moderately diminished. Overstimulation of Hog1p by deletion of the genes for the protein phosphatases PTP2 and PTP3 led to higher basal and induced mRNA levels and a shorter lag phase. The protein phosphatase calcineurin, which mediates salt-induced expression of some genes, does not appear to contribute to the control of GPD1 expression. Although GPD1 expression has so far not been reported to be controlled by a general stress response mechanism, heat-shock induction of the GPD1 mRNA level was observed. However, unregulated protein kinase $A$ activity, which strongly affects the general stress response, only marginally altered the mRNA level of GPD1. The osmotic stimulation of GPD1 expression does not seem to be mediated by derepression, since deletion of the SSN6 gene, which encodes a general repressor, did not significantly alter the induction profile. A hypoosmotic shock led to a transient 10-fold drop of the GPD1 mRNA level. Neither the HOG nor the protein kinase C pathway, which is stimulated by a decrease in external osmolarity, is involved in this effect. It was concluded that osmotic regulation of GPD1 expression is the result of an interplay between different signalling pathways, some of which remain to be identified.
\end{abstract}

Keywords: osmotic stress, signal transduction, high osmolarity glycerol (HOG) pathway, protein kinase $A$, yeast

\section{INTRODUCTION}

The ability to adapt to altered osmolarity of the surrounding growth medium is of fundamental im- portance for uni- and multicellular organisms. A strategy in osmoadaptation probably employed by all cell types is the production and accumulation of compatible osmolytes to adjust the intracellular osmolarity to that

†Present address: Department of Microbiology, University of Stellenbosch, Private Bag XI, 7602 Matieland, South Africa.

Abbreviations: $\mathrm{HOG}$, high osmolarity glycerol; MAPK, mitogen-activated protein kinase; PKA, protein kinase $A ;$ PKC, protein kinase $C$; STRE, stress response element. 
of the growth medium (Yancey et al., 1982). Such osmolytes are species- and stage-specific and comprise ions, sugars, sugar alcohols and amino acids and their derivatives. We have studied the response of the yeast Saccharomyces cerevisiae to osmotic stress as a eukaryotic model system for molecular mechanisms in osmoadaptation. This organism employs glycerol as osmolyte (Blomberg \& Adler, 1992; Brown \& Edgley, 1980; Hohmann, 1997).

Glycerol is produced in two enzymic steps from the glycolytic intermediate, dihydroxyacetone phosphate (Gancedo et al., 1968; Prior \& Hohmann, 1997). The two enzymes are each encoded by two highly homologous isogenes: GPD1 and GPD2 encode glycerol-3phosphate dehydrogenase and GPP1 and GPP2 encode glycerol-3-phosphatase (Albertyn et al., 1994; Ansell et al., 1997; Eriksson et al., 1995; Larsson et al., 1993; Norbeck et al., 1996). The expression of these genes appears to be differentially regulated in response to altered growth conditions. Expression of GPD2 and GPP1 is stimulated under anaerobic conditions, when glycerol production becomes essential for redox regulation (Ansell et al., 1997; A.-K. Påhlman \& L. Adler, unpublished results). Transcription of GPD1 and GPP2 is stimulated by an increase in external osmolarity (Albertyn et al., 1994; Ansell et al., 1997; Hirayama et al., 1995; Hohmann, 1997; Norbeck et al., 1996).

The molecular mechanisms by which alterations in external osmolarity mediate responses in gene expression are of major interest. In yeast, two well studied signal transduction pathways are known to be rapidly stimulated by changes in osmolarity (Banuett, 1998; Hohmann, 1997). The high osmolarity glycerol (HOG) response pathway consists of two putative transmembrane osmosensors, Sho1p and $S \ln 1 \mathrm{p}$, and a branched mitogen-activated protein kinase (MAPK) cascade with Hog1p as the sole terminal MAPK (Brewster et al., 1993; Maeda et al., 1994, 1995; Posas \& Saito, 1997, 1998; Posas et al., 1996). Phosphorylation of Hog $1 \mathrm{p}$ is stimulated by increased external osmolarity within about $1 \mathrm{~min}$ (Brewster et al., 1993; Maeda et al., 1994, 1995; Siderius et al., 1997). The phosphorylation state of Hog $1 \mathrm{p}$ is controlled not only by upstream kinases but also by the protein phosphatases Ptp2p and Ptp3p (Jacoby et al., 1997; Wurgler-Murphy et al., 1997). The protein kinase $C$ (PKC) pathway also consists of a MAPK cascade with Slt2/Mpk1p as the terminal MAPK (Irie et al., 1993; Lee et al., 1993; Lee \& Levin, 1992; Levin \& Errede, 1995; Levin et al., 1990; Martin et al., 1993). Phosphorylation of Slt2/Mpk1p has been shown to be rapidly stimulated by a decrease in external osmolarity by unknown sensing mechanisms (Davenport et al., 1995). In addition to these osmosensing pathways, there is a signalling route specifically required for the adaptation to high salt but not to general osmotic stress (Danielsson et al., 1996; Hirata et al., 1995; Mendoza et al., 1994). This pathway includes the protein phosphatase calcineurin, which consists of a catalytic and a regulatory subunit (Stark, 1996). The catalytic subunit is redundantly encoded by the genes
CNA1/CMP1 and CNA2/CMP2 (Cyert et al., 1991; Liu et al., 1991) while the regulatory subunit is encoded by CNB1 (Cyert \& Thorner, 1992).

Yeast cells not only have specific stress response mechanisms but also respond to stress in general (Ruis \& Schüller, 1995 ; Siderius \& Mager, 1997). The general stress response is at least partly controlled by protein kinase A (PKA) and mediated redundantly by transcription factors Msn2p and Msn4p which bind to so called stress response elements (STREs) in the promoters of many genes (Belazzi et al., 1991; Boy-Marcotte et al., 1998; Görner et al., 1998; Mager \& de Kruijff, 1995; Marchler et al., 1993; Martinez-Pastor et al., 1996; Siderius \& Mager, 1997).

The osmotic induction of several genes has been reported to depend on the HOG pathway or on PKA or on a combination of both (Albertyn et al., 1994; Hirayama et al., 1995; Márquez \& Serrano, 1996; Norbeck et al., 1996; Schüller et al., 1994; Varela et al., 1995). In this work we have studied in time course experiments the control of the mRNA level of the GPD1 gene after an increase or a decrease in external osmolarity. This analysis reveals that the HOG pathway plays an important, albeit not exclusive, role in osmotic induction of GPD1 expression, while PKA only contributes marginally, if at all, to osmotic induction. It also appears that osmotic control of GPD1 expression is the result of an interplay between different signalling pathways, some of which remain to be identified.

\section{METHODS}

Plasmid and yeast strain constructions. The yeast strains used in this study are listed in Table 1 . The construction of the hog1 1 : :TRP1 deletion mutant has been described previously (Albertyn et al., 1994; Brewster et al., 1993). In some strains the entire coding region of HOG1 was deleted by a PCR approach (Eberhardt \& Hohmann, 1995). The SLT2/MPK1 gene was deleted in W303-1A as described by Lee et al. (1993) and PTP2 was deleted according to Maeda et al. (1993). To delete PTP3 the gene plus its flanking regions were amplified by PCR and cloned into pUC18. A ptp3 $3:$ URA3 deletion construct was made by replacing a $B g l \mathrm{II}$ fragment, covering the region from -22 (relative to the translational start codon) to +2738 ( 49 bp before stop codon), by a BamHI fragment with the URA3 gene from YDpU (Berben et al., 1991). The strains YMR 88 (ptp2 $2::$ LEU2 ptp3 $3:: U R A 3)$ and YMR 90

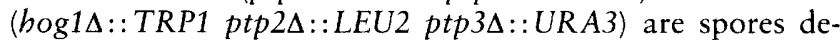
rived from a cross between YMR 86 (ptp3 3 ::URA3) and YSH

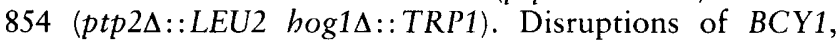
TPK1 and TPK2 were transferred from their original background (SP1) into W303-1A by transformation with DNA fragments containing the respective disruption alleles. These were amplified by PCR from chromosomal DNA of strains RS13-58A-1 (the tpk2::HIS3 allele) and RS13-7C-1 (the bcy1::LEU2 and tpk1 $1::$ URA3 alleles; Nikawa et al., 1987). The mutations were combined with each other and with a

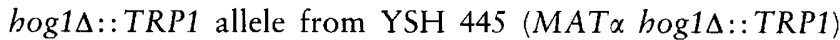
through several rounds of crossing and sporulation to obtain strains YMR 70 (tpk1 $1:$ URA3 tpk2::HIS3), YMR 72 (tpk14::URA3 tpk2::HIS3 bcy1::LEU2) and YMR 93

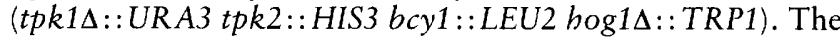
ssn6 $\Delta$ strain YMR 125 was constructed from MAP6 (kindly 
Table 1. Strains used

\begin{tabular}{|c|c|c|}
\hline Strain & Genotype & Source or reference \\
\hline W303-1A & MATa leu2-3/112 ura3-1 trp1-1 his3-11/15 ade2-1 can1-100 GAL SUC2 malo & Thomas \& Rothstein (1989) \\
\hline YSH 849 & (W303-1A) $m p k 1 \Delta:: T R P 1$ & This work \\
\hline YSH 444 & (W303-1A) hog1 $1:$ TRP1 & Albertyn et al. (1994) \\
\hline YSH 445 & (W303-1A) MAT $\alpha$ hog1 $1:: T R P 1$ & This work \\
\hline DHT23-1B & 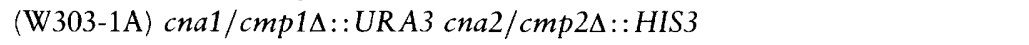 & Nakamura et al. (1993) \\
\hline YSH 816 & (W303-1A) ptp2s::LEU2 & This work \\
\hline YMR 86 & (W303-1A) ptp3A::URA3 & This work \\
\hline YMR 88 & 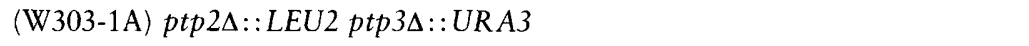 & This work \\
\hline YMR 90 & 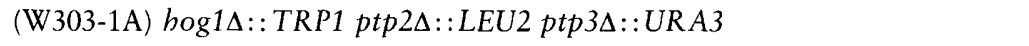 & This work \\
\hline YSH $7.50-2 B$ & 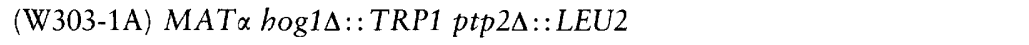 & This work \\
\hline YMR 70 & 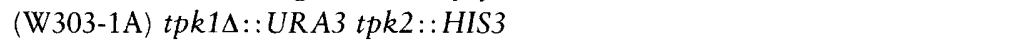 & This work \\
\hline YMR 73 & (W303-1A) tpk1 : :URA3 tpk2::HIS3 bcy1::LEU2 & This work \\
\hline YMR 92 & 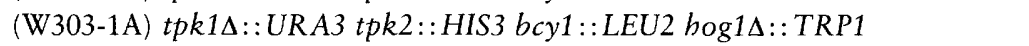 & This work \\
\hline SP1 & MATa leu 2 bis 3 trp1 ura 3 ade8 can1 SUC GAL malo & Toda et al. (1985) \\
\hline RS13-58A-1 & (SP1) tpk1 $1^{\mathrm{w} 1} t p k 2::$ HIS3 tpk3::TRP1 bcy1::LEU2 & Nikawa et al. (1987) \\
\hline RS13-7C-1 & 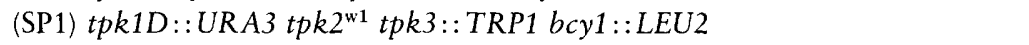 & Nikawa et al. (1987) \\
\hline W303-1A ADE2 & MATa leu2-3/112 ura3-1 trp1-1 bis3-11/15 can1-100 GAL SUC2 mal0 & Markus Proft, Valencia \\
\hline MAP6 & (W303-1A ADE2) ssn6::loxp-KAN-loxp & Markus Proft, Valencia \\
\hline YMR 125 & (W303-1A ADE2) ssn6::loxp & This work \\
\hline
\end{tabular}

provided by $\mathrm{M}$. Proft, Valencia) by removing the KAN marker using the pSH47 plasmid encoding the Cre recombinase (Guldener et al., 1996). The W303-1A ADE2 strain background is a direct derivative of W303-1A lacking the ade2 marker.

Media and growth conditions. Cells were grown on a rotary shaker at $30^{\circ} \mathrm{C}$ in $\mathrm{YP}$ medium $(2 \%$ peptone, $1 \%$ yeast extract) supplemented with a carbon source as indicated. Synthetic medium (SM) consisting of amino-acid-free yeast nitrogen base (Difco) and $2 \%$ glucose was described by Sherman et al. (1983). For stress induction experiments, cells were pregrown in YP medium containing $2 \%$ glucose (YPD) without osmotic adjustment (water activity $0.998 a_{\mathrm{w}}$ ) to midexponential phase $\left(\mathrm{OD}_{600}\right.$ between 0.7 and 1.5). For osmotic support, $0.5 \mathrm{M}$ sorbitol was added to the growth medium of the $s l t 2 / m p k 1 \Delta$ mutant. Osmotic stress was applied by adding $\mathrm{NaCl}$ to the cultures resulting in final concentrations of $0.5 \mathrm{M}$ $\mathrm{NaCl}\left(3 \% ; 0.980 a_{\mathrm{w}}\right), 0.85 \mathrm{M} \mathrm{NaCl}\left(5 \% ; 0.970 a_{\mathrm{w}}\right)$ or $1.4 \mathrm{M}$ $\mathrm{NaCl}\left(8 \% ; 0.954 a_{\mathrm{w}}\right)$. Alternatively, cells were sedimented and resuspended in YPD medium supplemented with $0.95 \mathrm{M}$ sorbitol $\left(0.980 a_{w}\right.$, equivalent to $\left.0.5 \mathrm{M} \mathrm{NaCl}\right)$ or $1.5 \mathrm{M}$ sorbitol $\left(0.970 a_{w}\right.$, equivalent to $\left.0.85 \mathrm{M} \mathrm{NaCl}\right)$. For osmotic downshock experiments cells were grown to mid-exponential phase in YPD medium supplemented with $0.85 \mathrm{M} \mathrm{NaCl}$ plus $0.5 \mathrm{M}$ sorbitol $\left(0.962 a_{\mathrm{w}}\right)$. Cells were sedimented and resuspended in YPD supplemented with $0.5 \mathrm{M}$ sorbitol but lacking $\mathrm{NaCl}$.

For heat stress, medium amounting to one-third of the culture volume was pre-heated to $66^{\circ} \mathrm{C}$ and added to the culture to give a final temperature of $42{ }^{\circ} \mathrm{C}$. Cells were then incubated in a water bath at $42{ }^{\circ} \mathrm{C}$ and samples taken at the times indicated. For entry into a non-proliferative phase, cells pregrown to either mid-exponential phase or stationary phase were reinoculated in fresh medium and growth was monitored until cells stopped dividing. For growth on a non-fermentable carbon source or for nitrogen starvation, cells were pregrown in YP medium containing $8 \%$ glucose, sedimented and resuspended in either YP medium containing 3\% ethanol for
$6 \mathrm{~h}$ (growth on a non-fermentable carbon source) or in SM without ammonium sulphate containing $8 \%$ glucose (for nitrogen starvation). Nitrogen starvation was conducted for $24 \mathrm{~h}$; there was still glucose present in the growth medium after this period. For glucose starvation experiments, cells were pregrown in YPD medium until exponential phase and resuspended in YP medium for $6 \mathrm{~h}$.

Northern blotting techniques. Total RNA was isolated at the time points indicated in the figures and separated by electrophoresis according to the method described by de Winde $e t$ al. (1996). Blots were hybridized in buffer containing $7 \%$ SDS, $0 \cdot 5 \mathrm{M}$ sodium phosphate buffer, $\mathrm{pH} 7 \cdot 2$, and $1 \mathrm{mM}$ EDTA. The signal was quantified using a phosphorimager (Fuji, BAS1000 ). The probes used were generated by PCR from chromosomal DNA of W303-1A. The GPD1 probe includes sequences from -527 to +95 relative to the start codon (this excludes sequences homologous to GPD2). Probes for CTT1 $(-14$ to +1007$)$, HSP12 $(-139$ to +493$)$ and SSA3 $(+3$ to +980) were kindly provided by $\mathrm{Dr}$ de Winde (Leuven, Belgium). Probe fragments were labelled with High Prime (Boehringer Mannheim).

As a loading control we have used an IPP1 probe, including sequences from +16 to +846 relative to the start codon. IPP1 encodes inorganic pyrophosphatase and the protein level was found to be entirely unaffected by osmotic shifts (Norbeck \& Blomberg, 1997; A. Blomberg \& J. Norbeck, personal communication). Commonly, ACT1, which encodes actin, has been used as a loading control. Comparison of the IPP1 and the ACT1 signals showed that the ACT1 level responds significantly to both hyper- and hypo-osmotic shock while that of IPP1 remains constant (data not shown).

Reproducibility of the data. Experiments were generally performed at least in duplicate or triplicate with consistent results, i.e. the differences between wild-type and mutants were highly reproducible. The relative mRNA levels differed from experiment to experiment by no more than $20 \%$. The results from representative experiments are shown. 


\section{RESULTS}

\section{Osmotic induction of GPD1 expression is transient and more severe osmotic stress leads to a progressive delay of the response}

We have monitored the mRNA level of GPD1 in time course experiments after a shift to higher osmolarity. When using either $0.5 \mathrm{M} \mathrm{NaCl}$ or $0.95 \mathrm{M}$ sorbitol, which both give the same water activity of $0.980 a_{\mathrm{w}}$, the induction curves were almost superimposable (Figs 1 and 2). Thus, the response is independent of the solute used. The response appeared to consist of different phases starting with an approximately 20 -fold induction within $30 \mathrm{~min}$. Subsequently, the mRNA level dropped to about the same level as before osmolyte addition, slowly increased again and then stayed four- to fivefold higher than before induction, even after prolonged incubation (Figs 1 and 2 and data not shown).

When higher osmolyte concentrations were used, such as $0.85 \mathrm{M} \mathrm{NaCl}$ and $1.5 \mathrm{M}$ sorbitol $\left(0.970 a_{\mathrm{w}}\right)$, the response was delayed and the highest GPD1 mRNA level was observed after about $2 \mathrm{~h}$ instead of $30-45 \mathrm{~min}$ at $0.980 a_{\mathrm{w}}$ (Figs 1 and 2). The maximal mRNA level during the initial induction was higher than at the lower solute concentration. After prolonged incubation the GPD1 mRNA level was 10-fold higher as compared to before the shift to higher osmolarity (data not shown).

When even higher salt concentrations $\left(1.4 \mathrm{M}, 0.954 a_{\mathrm{w}}\right)$ were applied, the response was shifted further to later time points, but also the induction profile differed. There was no apparent rapid induction but instead a slow increase to an about fivefold higher GPD1 mRNA level. Thus, the profile of osmotic induction of GPD1 expression is dependent on osmolyte concentrations.

\section{The HOG pathway is involved in the timing and determines the amplitude of the response}

The hog1 mutation affected GPD1 expression in different ways (Figs 1 and 2). First, the mRNA level of GPD1 was diminished both before and after osmotic (a)

$\mathrm{NaCl}(\mathrm{M}) \quad$ GPD1 IPP1
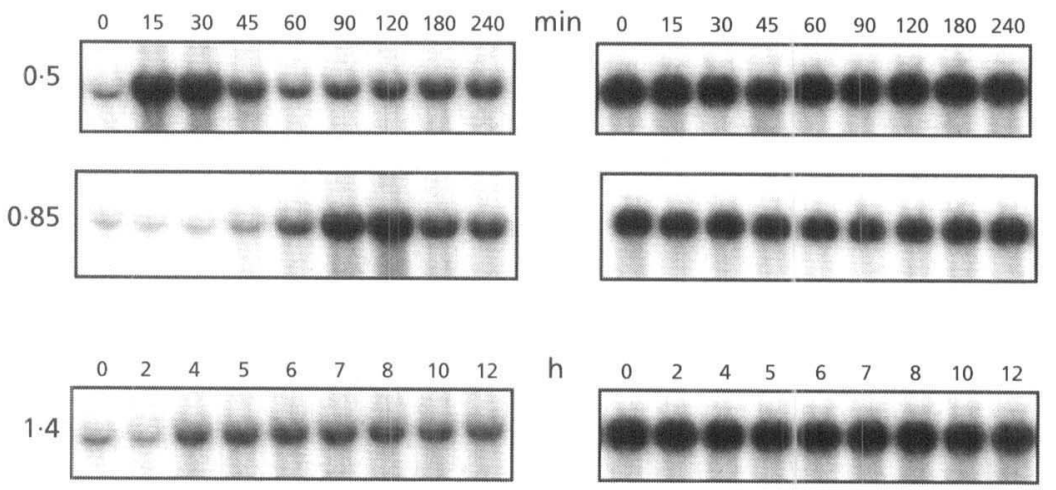

h

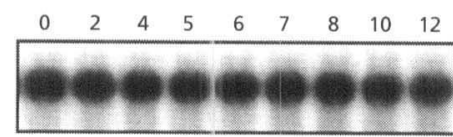

(b)

$\mathrm{NaCl}(\mathrm{M})$

GPD1
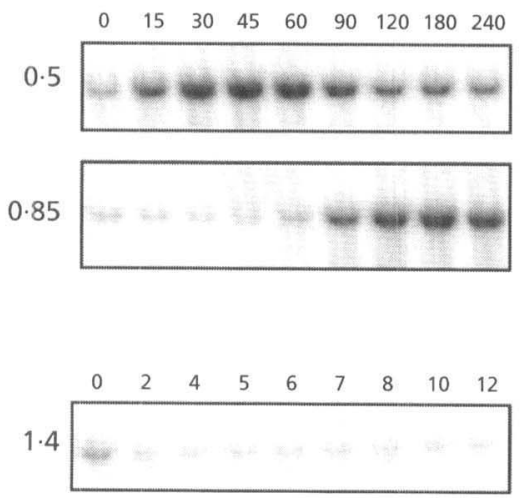

IPP1
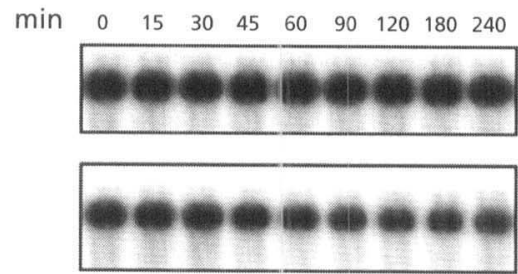

$\mathrm{h}$

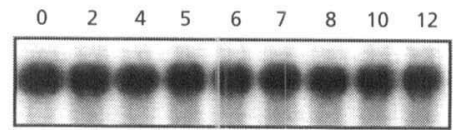

(c)
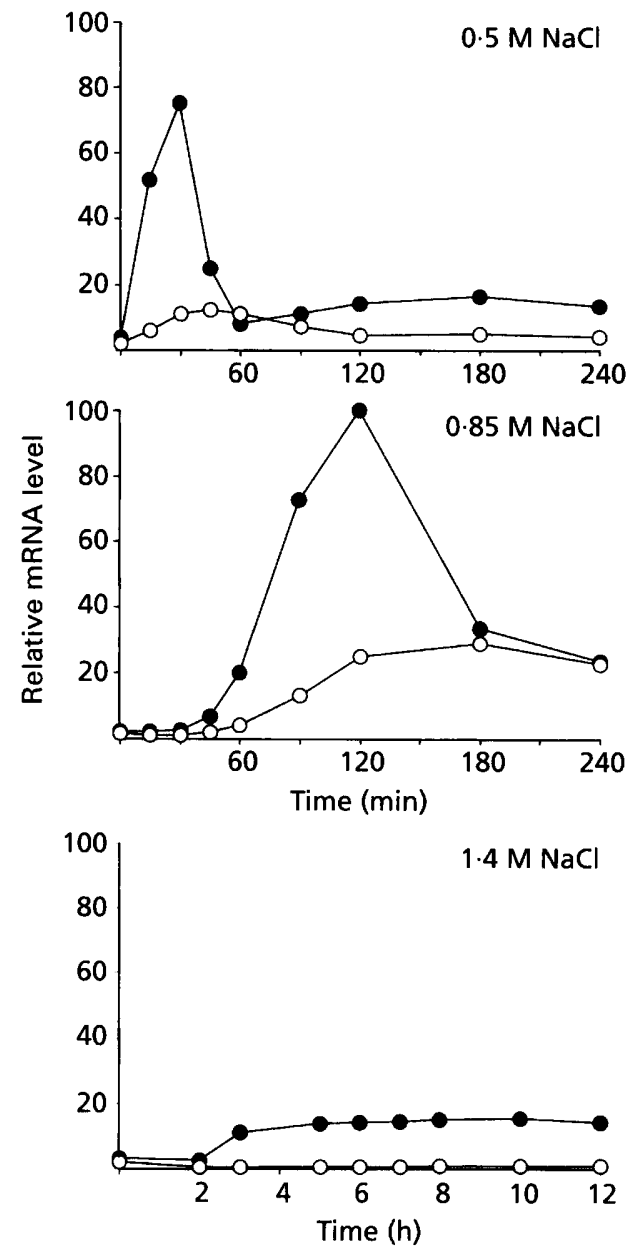

Fig. 1. GPD1 mRNA levels after a shift to higher $\mathrm{NaCl}$ concentrations in the wild-type (a) and the hog1 $\Delta$ mutant (b). (c) Graphs represent quantification of the MRNA levels relative to those of IPPI for the wild-type (Q) and the hog $1 \Delta$ mutant $(O)$. The highest relative mRNA level was set to 100 . 
(a)

Sorbitol (M)
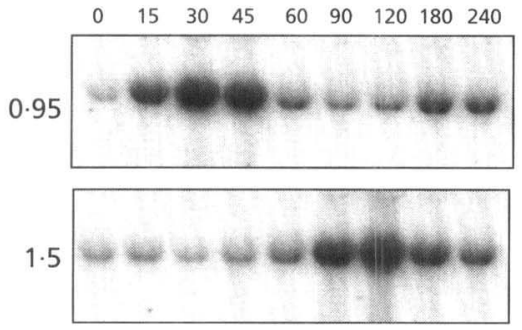

(b)

Sorbitol (M)

GPD1
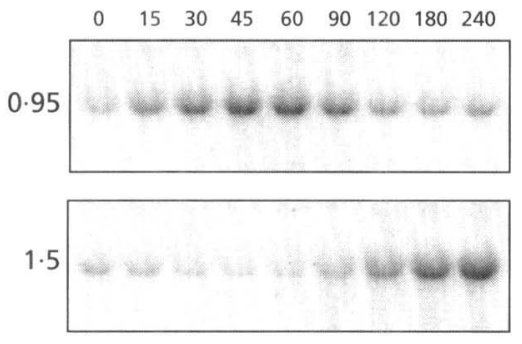

IPP1

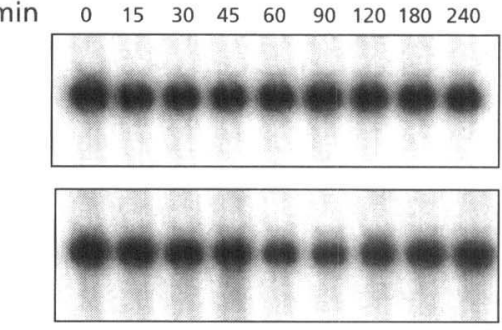

IPP1

$\begin{array}{llllllllll}\min & 0 & 15 & 30 & 45 & 60 & 90 & 120 & 180 & 240\end{array}$
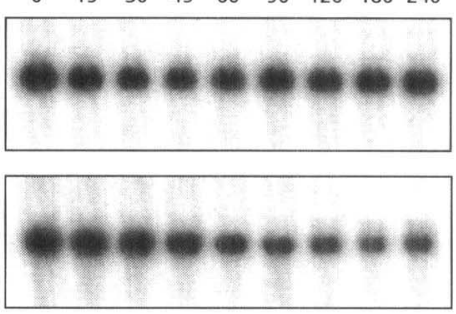

(c)
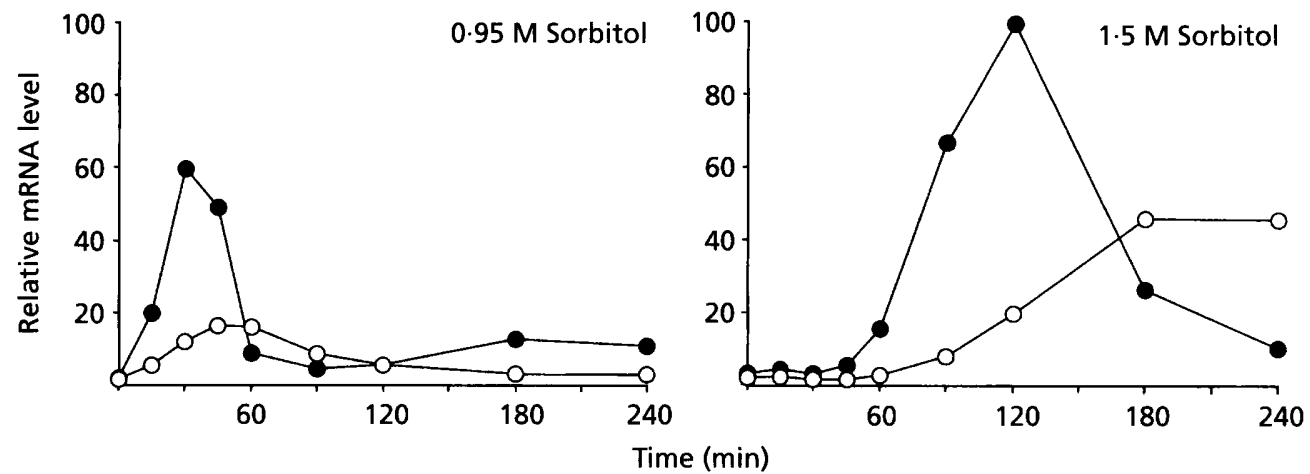

Fig. 2. GPD1 mRNA levels after a shift to higher sorbitol concentrations in the wild-type (a) and the hog1 $\Delta$ mutant (b). Sorbitol at $0.95 \mathrm{M}$ results in the same water activity of $0.980 a_{w}$ as $0.5 \mathrm{M} \mathrm{NaCl}$, and $1.5 \mathrm{M}$ sorbitol causes the same osmotic stress as $0.85 \mathrm{M} \mathrm{NaCl}\left(0.970 \mathrm{a}_{w}\right)$. (c) Graphs represent quantification of the mRNA levels relative to those of IPP1 for the wild-type (O) and the hog $1 \Delta$ mutant (O). The highest relative mRNA level was set to 100 .

shock. In addition, maximal induction was consistently shifted to later time points at the lowest and the intermediate solute concentration. At $1.4 \mathrm{M} \mathrm{NaCl}(0.954$ $\left.a_{\mathrm{w}}\right)$ the hog1 $1 \Delta$ mutant was unable to increase the GPD1 mRNA level within $12 \mathrm{~h}$ after the shift. The lack of induction is not due to cell death (data not shown) and the IPP1 mRNA level remained constant during the entire experiment.

Although expression of GPD1 was strongly affected in the $\operatorname{bog} 1 \Delta$ strain, we note that the mutant was able to mount a response after a shift to 0.980 and $0.970 a_{w}$. Maximal induction was diminished from about 20- to 25 -fold in the wild-type to about eightfold in the hog1 $\Delta$ mutant at $0.980 a_{\mathrm{w}}$ and from about 40 - to 20 -fold at $0.970 a_{w}$. After prolonged incubation at 0.970 and 0.980 $a_{\mathrm{w}}$, the GPD1 mRNA level was about half that of the wild-type and four-and eightfold higher as compared to before the upshift.

Since the hog1 $1 \Delta$ mutant is osmosensitive (Albertyn et al., 1994; Brewster et al., 1993) some of the effects observed in that strain, such as the delay in the response, could be due to secondary effects of the mutation and not to a specific involvement of the HOG signalling cascade. Therefore, we did the same time course experiment at $0.85 \mathrm{M} \mathrm{NaCl}$ with mutations in the PTP2 and PTP3 genes. These two genes encode protein phosphatases and deletion of PTP2 and PTP 3 increases the phosphorylation state (Jacoby et al., 1997; WurglerMurphy et al., 1997) and hence most probably the activity of Hog1p. Deletion of PTP2 and of PTP2 plus 
(a)

(b)
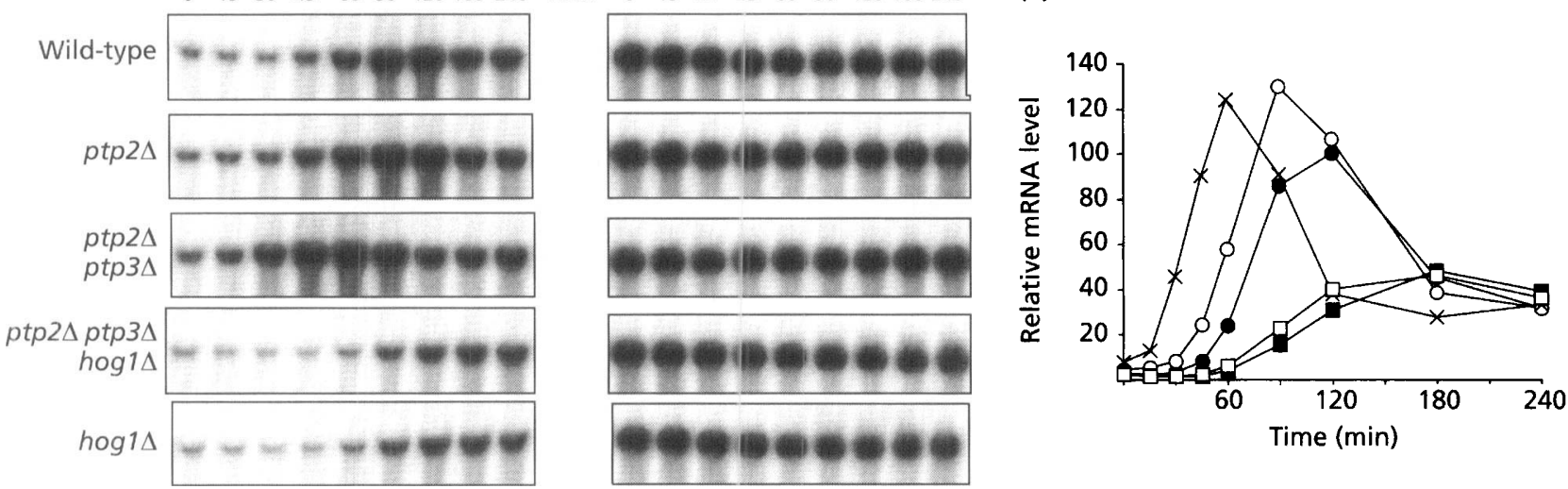

Fig. 3. (a) Osmotic induction of GPD1 mRNA levels by $0.85 \mathrm{M} \mathrm{NaCl}$ in mutants lacking the protein kinase Hog1p and/or the protein phosphatases Ptp2p and Ptp3p, which control Hog1p. (b) The graph represents relative mRNA levels for the wild-type (O) and the $\operatorname{ttp} 2 \Delta(0), \operatorname{ptp} 2 \Delta \operatorname{ptp} 3 \Delta(\times), p \operatorname{tp} 2 \Delta p \operatorname{tp} 3 \Delta$ hog $1 \Delta(\square)$ and hog $1 \Delta(\square)$ mutants. The highest relative mRNA level in the wild-type was set to 100 .

(a)

GPD1
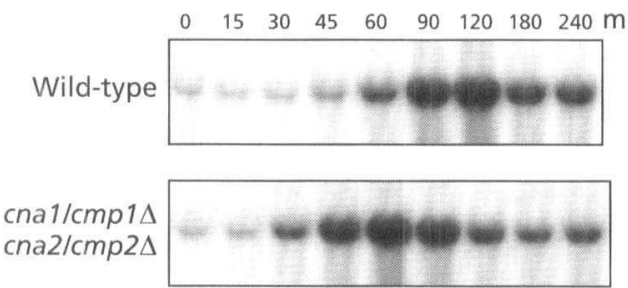

(b)

GPD1

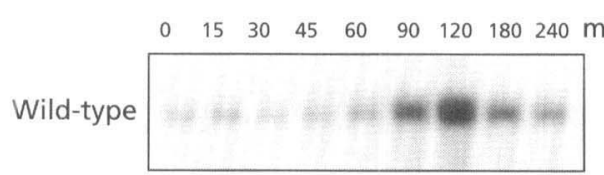

cna $1 / \mathrm{cmp} 1 \Delta$

cna2/cmp2 $\Delta$

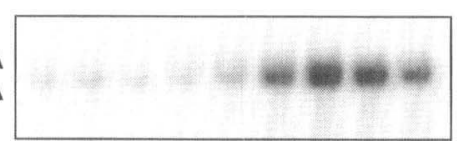

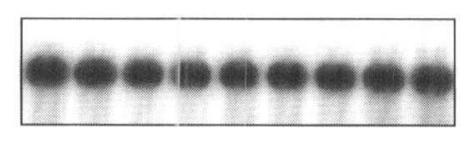

IPP1

IPP1
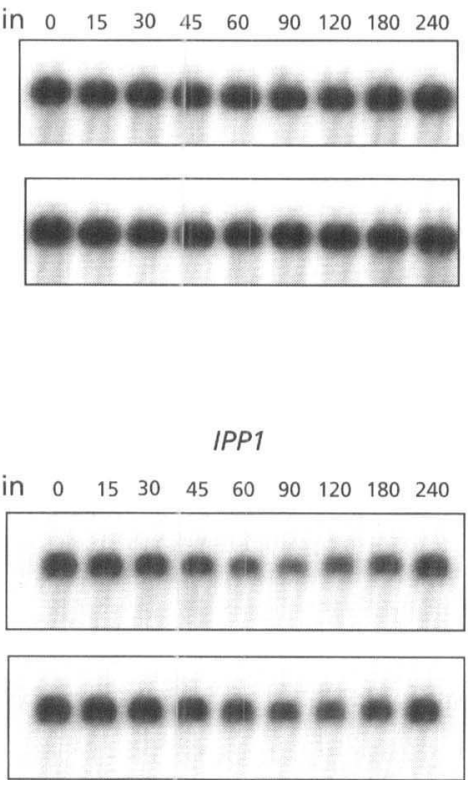
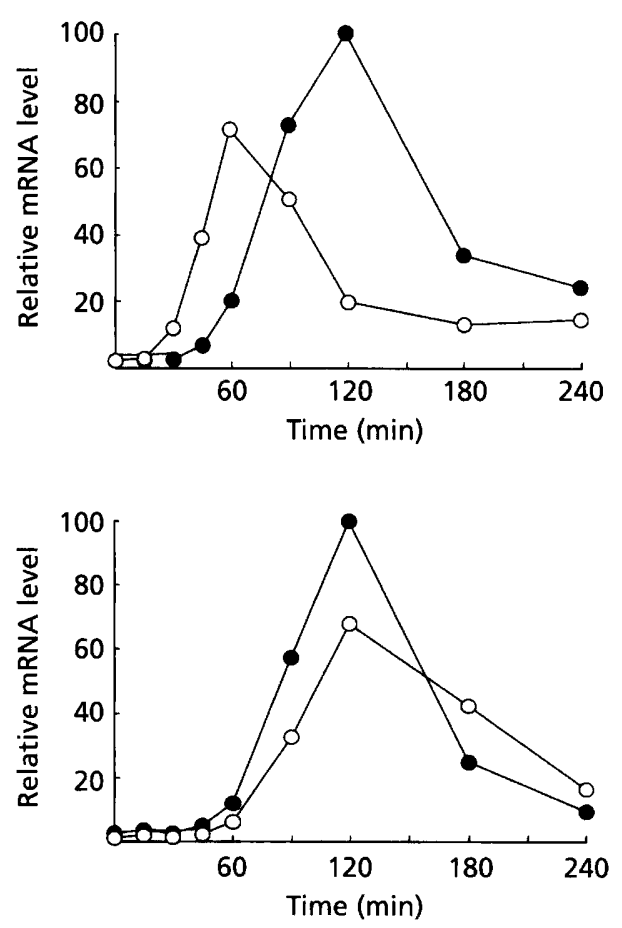

Fig. 4. Osmotic induction of GPD1 mRNA levels by $0.85 \mathrm{M} \mathrm{NaCl}$ (a) and $1.5 \mathrm{M}$ sorbitol (b) in the wild-type (a) and a cmp1 $\Delta$ cmp2 $\Delta$ mutant (O) which lacks the catalytic subunit of the protein phosphatase calcineurin. The highest relative mRNA level in the wild-type was set to 100 .

PTP3 led to a somewhat higher basal and induced level of the GPD1 mRNA and also shifted the response to earlier time points (Fig. 3). This observation is consistent with a direct involvement of the HOG pathway in controlling GPD1 expression. This is further confirmed by the fact that deletion of $H O G 1$ in a $p t p 2 \Delta p t p 3 \Delta$ double mutant resulted in exactly the same induction profile as in the hog $1 \Delta$ single mutant, as expected if 
PTP2 and PTP3 mediated their effect on GPD1 expression solely via Hog $1 \mathrm{p}$. The $p t p 2 \Delta$ and $p t p 2 \Delta p t p 3 \Delta$ mutations did not lead to an increased maximal induction since the basal level was already $1 \cdot 5$ - and $2 \cdot 5$ fold higher as compared to wild-type, respectively.

\section{The calcineurin protein phosphatase does not appear to mediate salt-induced expression of GPD1}

The calcineurin protein phosphatase has been shown to be required for the induction of expression of the PMR2/ENA1 gene by high salt concentrations but not by a general osmolarity upshift (Márquez \& Serrano, 1996). Mutants lacking the two genes for the catalytic subunit of the phosphatase are viable but display a complex phenotype, including salt sensitivity (Danielsson et al., 1996; Mendoza et al., 1994, 1996). We therefore tested the effect of the cna1/cmp1s cna1/cmp2s mutation on salt-induced expression of GPD1 at $0.85 \mathrm{M} \mathrm{NaCl}$. The induction profile was altered to some extent, i.e. maximal induction was diminished by about $30 \%$ and shifted to an earlier time point (Fig. 4a). This may point to some involvement of the calcineurin pathway. However, a similar reduction of maximal GPD1 induction was seen with sorbitol as osmolyte (Fig. 4b), even though sorbitol does not stimulate the calcineurin pathway (Márquez \& Serrano, 1996). Together with the absence of a salt-specific component in the induction of GPD1 expression in wildtype or hog1 $1 \Delta$ mutant (Figs 1 and 2), this leads us to believe the small reduction of GPD1 expression in the mutant does not point to a specific involvement of this pathway.

We have performed a similar time course experiment after a shift to $0.85 \mathrm{M} \mathrm{NaCl}$ with a slt $2 / m p k 1 \Delta$ mutant lacking the terminal protein kinase of the PKC pathway. This pathway can be stimulated by a hypo- but not by a hyperosmotic shock (Davenport et al., 1995). Neither basal nor induced GPD1 mRNA levels nor the induction profile was altered in this mutant (data not shown), confirming an earlier report that GPD1 expression is not affected by mutations in the PKC pathway (Hirayama et al., 1995).

\section{Induction of GPD1 expression is not mediated by the CAMP-PKA pathway}

The expression of several yeast genes is induced by any type of stress, i.e. by a general stress response, which is mediated by so-called STREs in the promoter of the target genes (Kobayashi \& McEntee, 1993; Mager \& de Kruijff, 1995; Marchler et al., 1993; Martinez-Pastor et al., 1996; Ruis \& Schüller, 1995; Siderius \& Mager, 1997; Varela et al., 1995). There are three such elements in the GPD1 promoter at positions $-330,-186$ and -34 . To investigate if expression of GPD1 is stimulated by other stress types, we have performed Northern blotting analysis after a shift to higher temperature (Fig. 5), after entry into the non-proliferative growth phase (pre-stationary phase), during nitrogen starvation and (a)
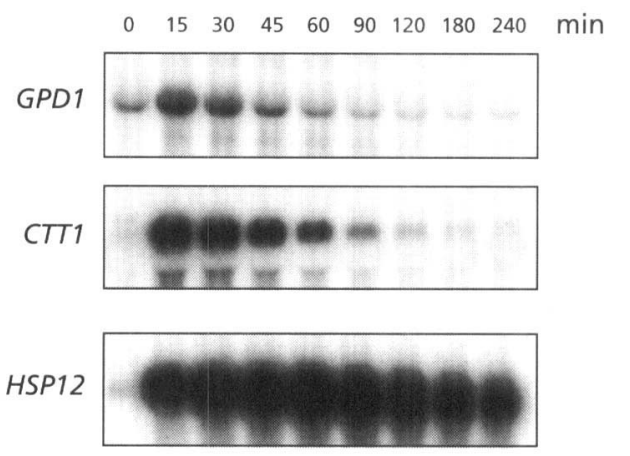

$18 S$ rRNA

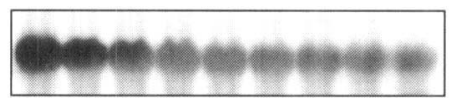

(b)

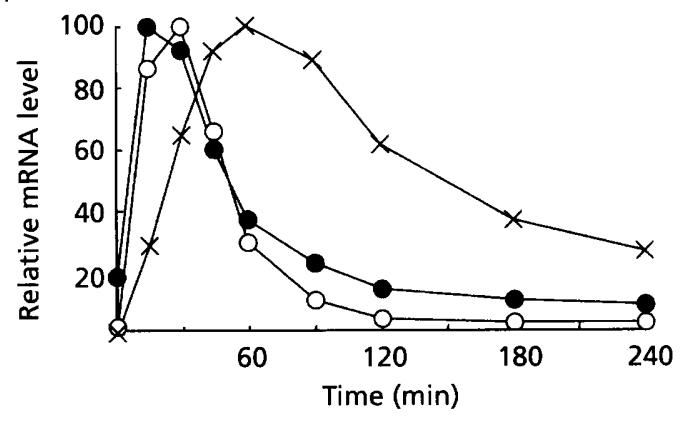

Fig. 5. mRNA levels, after a shift to $42^{\circ} \mathrm{C}$, of GPD1 (O), CTT1 (O) which encodes cytosolic catalase T and HSP12 (x) which encodes a small heat-shock protein. (a) Northern blot, (b) quantification. Since the MRNA level of IPP1 as well as that of ACT1 steadily dropped after heat shock, 18S rRNA was employed as standard. The highest relative level of each mRNA was set to 100 .

during growth on a non-fermentable carbon source, all conditions known to stimulate expression of genes controlled by STREs. Only heat shock caused about a fivefold stimulation of the GPD1 mRNA level (Fig. 5). The induction was equally rapid as that of CTT1. Apparently, expression of GPD1 can also be controlled by stress conditions other than high osmolarity. We have used $18 \mathrm{~S} \mathrm{rRNA}$ in this experiment as standard for the quantification, since both IPP1 and ACT1 mRNA (data not shown) decrease dramatically during the time course, perhaps due to a general reduction of transcription of non-stress genes under these conditions. Although $18 \mathrm{~S}$ rRNA also decreases initially, it correlates better with the total RNA loaded.

The general stress response is strongly influenced by PKA, which controls the localization of the STREbinding protein Msn2p (Belazzi et al., 1991; Görner et al., 1998; Marchler et al., 1993; Martinez-Pastor et al., 1996; Ruis \& Schüller, 1995). High PKA activity leads to low expression of STRE-controlled genes and low PKA activity leads to high expression of such genes. We wished to investigate the role of the cAMP-PKA pathway 
(a)

GPD1

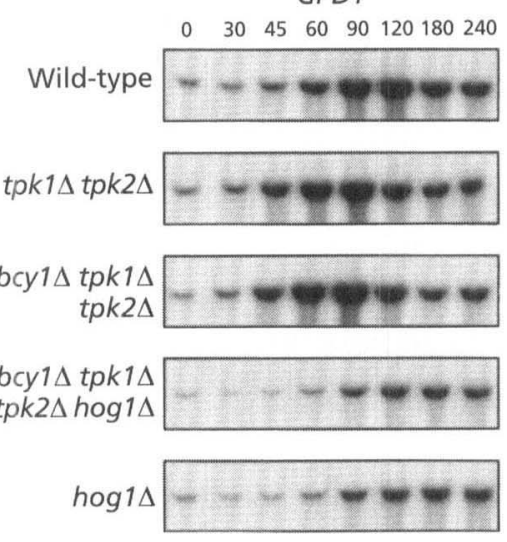

HSP12

$\begin{array}{lllllll}0 & 30 & 45 & 60 & 90 & 120 & 180240 \mathrm{~min} \quad 0\end{array}$
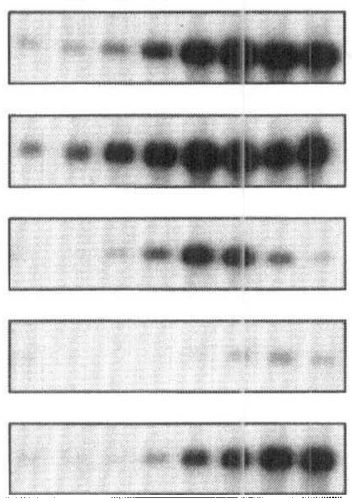

CTT1

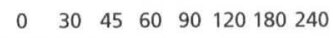
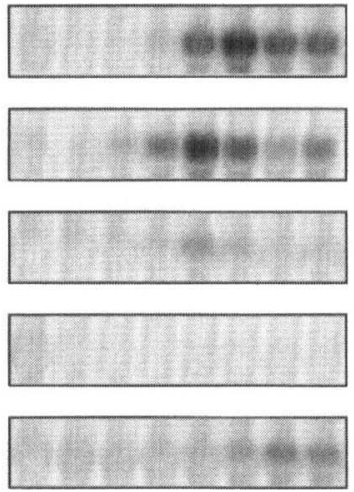

IPP1

$\begin{array}{lllllll}30 & 45 & 60 & 90 & 120 & 180 & 240\end{array}$
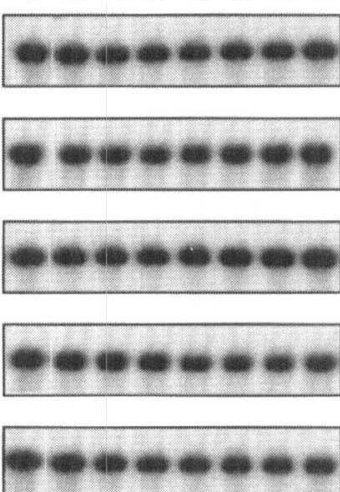

(b)

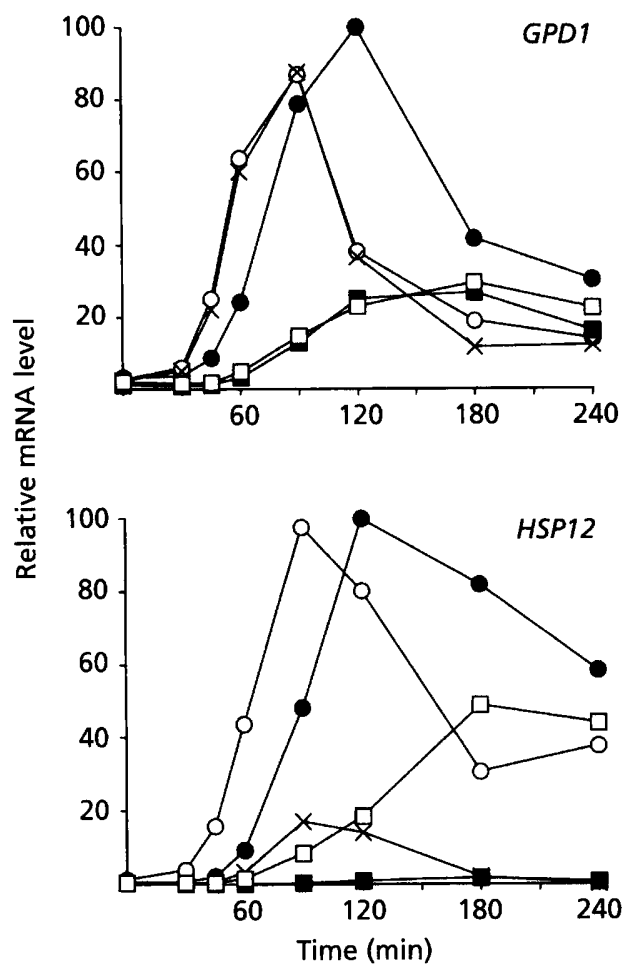

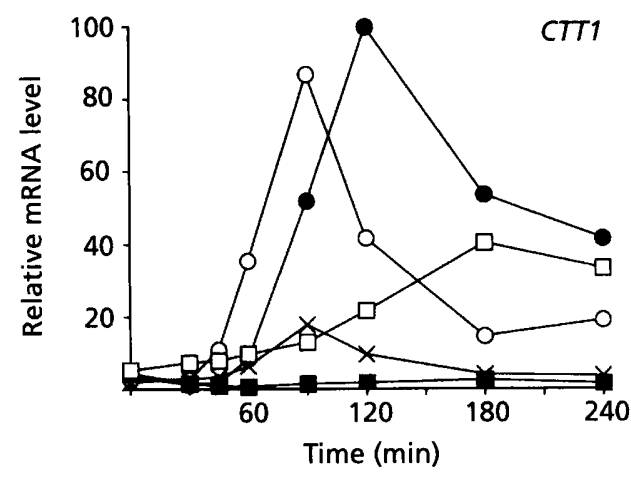

CTI1

Fig. 6. (a) Osmotic induction of the mRNA levels of GPD1, CTT1 and $H S P 12$ by $0.85 \mathrm{M} \mathrm{NaCl}$ in mutants affected in PKA activity. (b) For the quantification the highest relative mRNA level for each gene was set to 100 . The strains used were wild-type (O), a tpk $1 \Delta$ tpk2 mutant (O) which has low PKA activity, a tpk1 tpk2 bcy1 mutant $(x)$ which has unregulated PKA activity, a

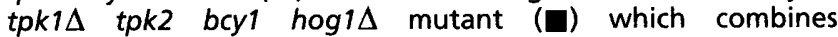
unregulated PKA activity with inactivation of the HOG pathway and a hog $1 \Delta$ single mutant $(\square)$.

in control of GPD1 expression. To this end, we used a

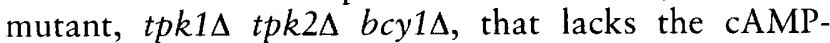
binding subunit of PKA. TPK3, the only gene encoding a catalytic subunit of PKA in this strain, is expressed at a very low level (Mazon et al., 1993). Therefore, this strain does not show the characteristic phenotypes of strains with high, unregulated, PKA activity (like stress sensitivity) but just lacks cAMP-PKA signalling. The $t p k 1 \Delta t p k 2 \Delta$ strain was used to assess the effect of low PKA activity.

Low PKA activity did not cause higher basal expression of any of the three genes but the induction was shifted to a slightly earlier time point in all cases (Fig. 6). This weak effect of low PKA activity on STRE-controlled genes contrasts with earlier findings (Marchler et al., 1993; Martinez-Pastor et al., 1996). Possibly, the activity of the TPK3 gene, although low, is still higher than that of the more generally used TPK-attenuated alleles. Maximal induction was unaffected. Unregulated PKA activity caused strongly diminished levels of CTT1 and HSP12 mRNA while the profile of GPD1 induction was identical to that observed in the mutant with low PKA activity. Hence, PKA activity does not appear to control GPD1 expression or at least not in the same way as expression of CTT1 and HSP12.

Induction of CTT1 and HSP12 expression after a shift to $0.85 \mathrm{M} \mathrm{NaCl}$ was delayed and diminished in a $b o g 1 \Delta$ strain in very much the same way as observed for GPD1. This behaviour has been reported previously for HSP12 (Siderius et al., 1997). In the quadruple mutant having

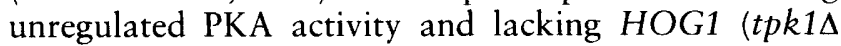
$t p k 2 b c y 1 \operatorname{hog} 1 \Delta)$, there was no apparent induction of 
(a)

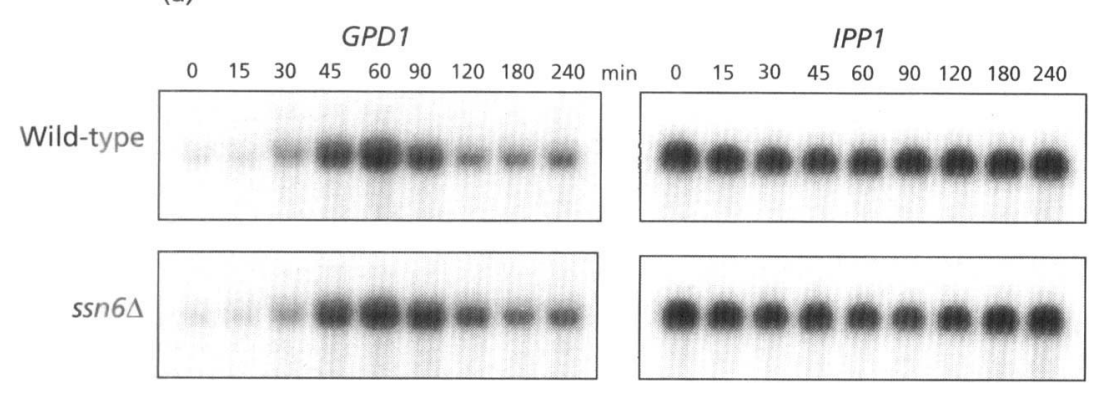

(b)

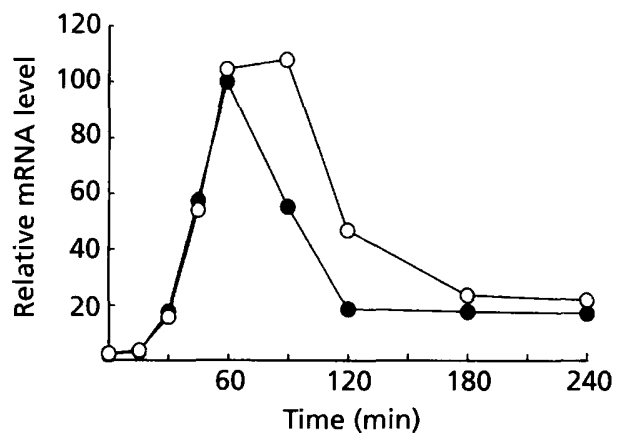

Fig. 7. Osmotic induction of GPD1 mRNA levels by $0.85 \mathrm{M} \mathrm{NaCl}$ in the wild-type (O) and a ssn6 6 mutant (O) deficient in the general repressor complex Ssn6p-Tup1p. (a) Northern blot, (b) quantification. The highest relative mRNA level in the wild-type was set to 100 .

(a)

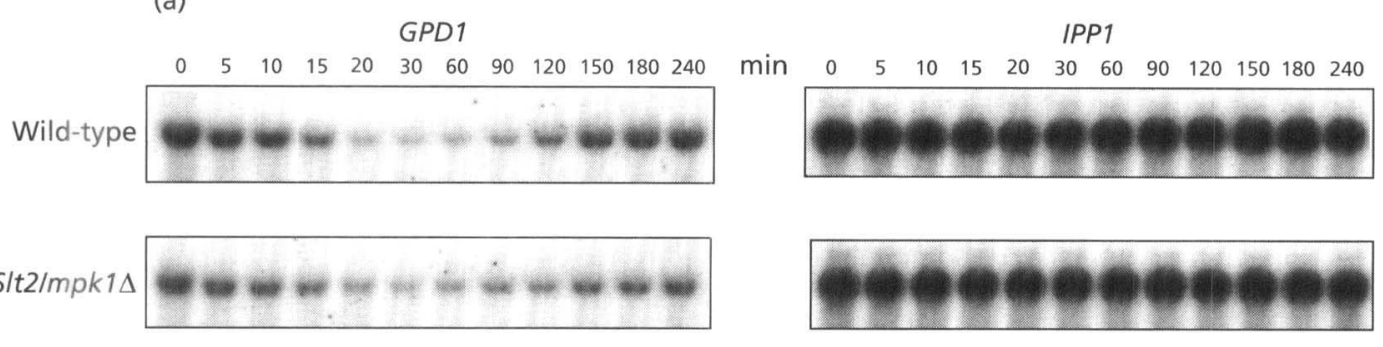

(b)

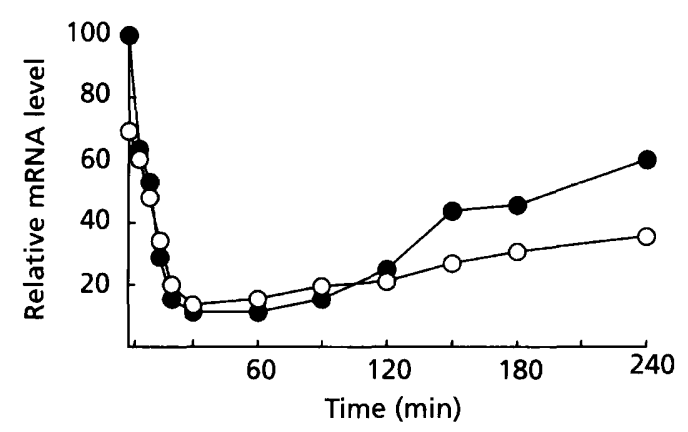

Fig. 8. GPD1 mRNA levels after a hypo-osmotic shock from $0.85 \mathrm{M} \mathrm{NaCl}$ to medium lacking salt in the wild-type (O) and the mpk $1 \Delta$ mutant $(O)$ which is defective in the PKC pathway. (a) Northern blot, (b) quantification. The highest relative mRNA level was set to 100 .

CTT1 and only a very minor increase in the level of HSP12 mRNA. The induction profile of GPD1 was essentially the same as in the hog $1 \Delta$ single mutant. Thus, also in combination with the hog1s mutation, unregulated PKA activity neither affected the GPD1 mRNA level nor its osmotic induction. In contrast, the osmotic response of CTT1 seems to depend exclusively and that of HSP 12 mainly (i.e. about $98 \%$ ) on the combined activity of the HOG and the PKA pathways.

\section{Induction of GPD1 does not involve a depression mechanism employing SSN6}

It has been reported that osmotic induction of some genes, including GPD1, is mediated by derepression and that repression under non-stress conditions is due to the
Ssn6p-Tup1p general repressor complex (Keleher et al., 1992; Márquez et al., 1998; Roth, 1995). In contrast to these recent findings (Márquez et al., 1998) we have found no evidence for repression of GPD1 transcription under non-stress conditions by Ssn6 (Fig. 7). The induction profile in wild-type and $\operatorname{ssn} 6 \Delta$ cells was very similar. Only the feedback phase is prolonged in the mutant with GPD1 mRNA levels returning to an only slightly elevated level as compared to wild-type after $3 \mathrm{~h}$. It should be noted that the response to $0.85 \mathrm{M} \mathrm{NaCl}$ of the strains used in this experiment is much more rapid than that of the other strains used in this study. This may be due to the absence of the ade 2 mutation in the W303$1 \mathrm{~A}$ derived background (Table 1). The ade 2 mutation is known to affect growth phenotypes and may influence the extent of pre-adaptation to stress. 


\section{The GPD1 mRNA level drops after a hypo-osmotic shock and this effect is independent of the PKC pathway}

We have monitored the GPD1 mRNA level after a drop in external osmolarity. For this, cells were pregrown in medium containing $0.85 \mathrm{M} \mathrm{NaCl}$ and shifted to medium lacking $\mathrm{NaCl}$. Cells were fully adapted to high osmolarity before the hypo-osmotic shock and hence the mRNA level was well below the fully induced level observed in the transient induction phase after a hyperosmotic shock. Hypo-osmotic shock caused a 10fold drop of the mRNA level within $30 \mathrm{~min}$ (Fig. 8). Subsequently, the GPD1 mRNA level slowly increased again to about half of the initial level. A very similar profile was observed when sucrose was used as an osmolyte instead of $\mathrm{NaCl}$ (data not shown).

The same experiment was also performed with a slt $2 / m p k 1 \Delta$ mutant, which lacks the terminal protein kinase of the PKC pathway. The profile and the maximal drop in the mRNA level was essentially the same as in the wild-type, except for a slower subsequent increase and a somewhat lower level $(70 \%)$ before the shift (Fig. $8)$. Thus, the PKC pathway does not mediate the transient drop of the GPD1 mRNA level after a hypoosmotic shock. In a similar experiment with the hog1 $1 \Delta$ mutant we could also not find evidence for the involvement of the HOG pathway in the response of GPD1 expression to a drop in external osmolarity (data not shown).

\section{DISCUSSION}

We have studied the control of the GPD1 mRNA level by changes in external osmolarity in time course experiments. This experimental setup has allowed us to define different phases in the response and we could show that the solute concentration but not the type of solute affects these phases. By doing the same type of experiments with mutants defective in four different stress-inducible pathways, we have confirmed our previous observation that the HOG pathway plays a central role in osmotic induction of GPD1 expression. However, there is a significant HOG-independent osmotic response. Since none of the three other pathways studied seems to be involved, the signalling pathway(s) mediating the HOG-independent response remain to be identified. We also show that a hypo-osmotic shock causes a strong, transient drop in the GPD1 mRNA level, which is independent of the PKC pathway.

\section{Osmotic induction of GPD1 expression}

The response of the GPD1 mRNA level to a shift to higher external osmolarity occurs in at least four distinct phases and their timing, amplitude and occurrence depend on solute concentration but are independent of the nature of the osmolyte. We define those phases as a lag phase, an initial induction phase, a feedback phase and a sustained induction phase.

At the lowest solute concentrations applied $\left(0.980 a_{\mathrm{w}}\right)$ the mRNA level increased instantaneously while after a shift to $0.970 a_{w}$ there was a lag phase of $30-45 \mathrm{~min}$ before the GPD1 mRNA level increased. At the highest salt concentration the lag phase was as long as $2-3 \mathrm{~h}$. Thus, some adaptation mechanism appears to be required after the osmotic shift before the expression of the GPD1 gene is stimulated. Since the lag phase is even longer in the hog1s mutant and since Hog $1 \mathrm{p}$ phosphorylation is stimulated rapidly after an osmotic upshift (Maeda et al., 1994, 1995), it is possible that the HOG pathway is involved in this adaptation process. The observation that the lag phase is much shorter ( $15 \mathrm{~min}$ instead of $45 \mathrm{~min}$ ) in a $p t p 2 \Delta p t p 3 \Delta$ strain, in which Hog $1 \mathrm{p}$ is hyperphosphorylated, is consistent with an involvement of the HOG pathway in the early recovery from osmotic shock.

This initial induction phase is clearly affected by inactivation of the HOG pathway, consistent with the observation that Hog1p phosphorylation upon osmotic shock is rapid and transient (Maeda et al., 1994, 1995). The maximal level of GPD1 mRNA is only about $15-20 \%$ of wild-type and the induction is delayed. However, the amplitude of this delayed GPD1 induction at 0.980 and $0.970 a_{\mathrm{w}}$ is still $6-10$-fold and 15-20-fold, respectively, revealing an important $\mathrm{HOG}$-independent component in GPD1 induction. This component may involve the sustained induction of GPD1, since steadystate GPD1 levels increase with osmolarity in a hog1 mutant, reaching roughly half of the wild-type levels (data not shown).

After the initial induction the GPD1 mRNA level drops again rapidly to almost the same level as before the osmotic shift. This feedback phase is best observed at $0.980 a_{\mathrm{w}}$ and takes about the same time as the initial induction, i.e. about $30 \mathrm{~min}$. The molecular nature of this feedback mechanism is unknown. It also occurs in the hog $1 \Delta$ (Figs 1 and 2) and the slt $2 / m p k 1 \Delta$ (data not shown) mutants and is hence at least in part independent of the HOG and the PKC pathways. We are employing time course experiments in which we monitor different events in osmotic adaptation in parallel to better understand the basis for the feedback mechanism.

As best defined at $0.980 a_{\mathrm{w}}$, the feedback phase is followed by a slow increase in the GPD1 mRNA level to a constant higher mRNA level. The final level correlates with the solute concentration, i.e. the higher the solute concentration, the higher the mRNA level in fully adapted cells (Ansell et al., 1997). The induction profile at the highest salt concentration $\left(1.4 \mathrm{M} \mathrm{NaCl} ; 0.954 a_{\mathrm{w}}\right)$ can be interpreted such that the initial induction phase and hence the feedback phase are missing and that the observed response is only due to this sustained induction phase. The sustained GPD1 mRNA level at this high salt concentration appears to be lower than that at $0.970 a_{\mathrm{w}}$. The correlation between lower water activity and higher GPD1 levels does not appear to hold at these extreme conditions.

Since all these phases are also observed when the GPD1 promoter is fused to a lacZ reporter gene and lacZ 
mRNA levels are taken as a measure for the promoter activity of GPD1, we believe that the phases are all due to transcriptional events (unpublished observations).

\section{Signalling pathways in osmotic induction of GPD1 expression}

Out of the four stress-inducible signalling pathways studied in this work only the HOG pathway contributes significantly to the control of GPD1 expression. Deletion of the genes encoding the catalytic subunit of the calcineurin protein phosphatase, which controls ion homeostasis in yeast (Serrano, 1996; Serrano et al., 1997 ), caused a $30 \%$ reduction of maximal GPD1 levels upon osmotic shock. Since this happens both with $\mathrm{NaCl}$ and sorbitol, we believe that this marginal alteration is an unspecific effect of the mutation. As with the mutant with low PKA activity, the earlier response in $\mathrm{NaCl}$ may be a result of 'pre-adaptation' to stress, i.e. the mutations would mimic a mild stress situation.

The observation that altered PKA activity did not affect the response of GPD1 expression to increased osmolarity is in agreement with recent data, showing that there is no significant effect of the deletion of the genes MSN2 and MSN4 on the induction of GPD1 expression (M. Rep, U. Holzmüller, V. Reiser, J. M. Thevelein, S. Hohmann, G. Ammerer \& H. Ruis, unpublished results). These two genes encode the transcription factors that mediate the stress response controlled by PKA (Martinez-Pastor et al., 1996). This also suggests that under osmotic stress the STREs in the GPD1 promoter are either not functional or their function is compensated by other mechanisms. Since expression of GPD1 can be induced by heat shock and since there is no evidence for heat shock response elements in the GPD1 promoter, the STREs might be functional under such conditions.

As discussed above, the impact of the HOG pathway appears to be different for the different phases. The level of GPD1 expression seems to be lower under all conditions. Thus, the HOG pathway also seems to be active under normal growth conditions and not only after a shift to higher osmolarity. This is consistent with recent observations of the effects of a HOG1 deletion on glycerol transport and a synthetic growth defect of hog1 1 with other mutations (Tamás et al., 1999; $\mathrm{M}$. Rep, J. M. Thevelein \& S. Hohmann, unpublished results). Future work will address the question if the different phases and the distinct involvement of the HOG pathway in these phases have a basis in different molecular mechanisms.

Such mechanisms do not appear to involve derepression through the Ssn6/Tup1 complex (Cooper et al., 1994; Keleher et al., 1992; Márquez et al., 1998; Roth, 1995). Deletion of SSN6 does not have a major impact on either the basal level of GPD1 mRNA or its induction profile. We do not know why our results in this respect differ from the findings of Márquez et al. (1998). It might be due to the fact that we have conducted a time course experiment while in that study mRNA was isolated from cells grown to mid-exponential phase in medium with or without $1 \mathrm{M} \mathrm{NaCl}$.

A significant part of the osmotic response of GPD1 expression is mediated by a HOG-independent mechanism. Our analysis excludes the PKA, calcineurin and PKC pathways as being responsible or involved in this response. Since the pathways studied here are to our knowledge the only yeast signalling routes stimulated by an increase in osmolarity or by the salt concentration of the growth medium, a novel signalling route appears to control the HOG-independent response. This pathway responds to osmolarity and not only to salt, since the HOG-independent response could be triggered by both salt and sorbitol.

\section{Response to a hypo-osmotic shock}

When cells growing on high-salt medium were shifted to medium without salt, we observed a transient drop in the GPD1 mRNA level. Since neither the PKC pathway nor the HOG pathway (Fig. 8 and data not shown) seem to mediate this response; also, in this case, the signalling pathway(s) involved remains to be identified. It is possible that the pathway mediating the hypo-osmotic effect on the GPD1 mRNA level is the same one that controls the feedback phase of osmotic induction, but the genetic tools to study this possibility are presently not available.

\section{ACKNOWLEDGEMENTS}

We thank Drs Levin and Nakamura for providing plasmids, Dr de Winde for probes and Dr Proft for yeast strains. We acknowledge support from the Commission of the European Union via contracts BIO4-CT95-0161 to J.M.T. and S. H. and FMRX-CT96-0007 to J.M.T., from the Ministry of the Flemish Community (International Scientific Cooperation between Flanders and South Africa, contract BIL96/27 to J.M.T. and B.A.P.) and from the Foundation for Research Development (FRD) to B.A.P.

\section{REFERENCES}

Albertyn, J., Hohmann, S., Thevelein, J. M. \& Prior, B. A. (1994). GPD1, which encodes glycerol-3-phosphate dehydrogenase is essential for growth under osmotic stress in Saccharomyces cerevisiae and its expression is regulated by the high-osmolarity glycerol response pathway. Mol Cell Biol 14, 4135-4144.

Ansell, R., Granath, K., Hohmann, S., Thevelein, J. M. \& Adler, L. (1997). The two isoenzymes for yeast $\mathrm{NAD}^{+}$-dependent glycerol 3-phosphate dehydrogenase encoded by GPD1 and GPD2 have distinct roles in osmoadaptation and redox regulation. EMBO J 16, 2179-2187.

Banuett, F. (1998). Signalling in yeast: an informational cascade with links to the filamentous fungi. Microbiol Mol Biol Rev 62, 249-274.

Belazzi, T., Wagner, A., Wieser, R., Schanz, M., Adam, G., Hartig, A. \& Ruis, H. (1991). Negative regulation of transcription of the Saccharomyces cerevisiae catalase T (CTT1) gene by cAMP is mediated by a positive control element. EMBO J 10, 585-592.

Berben, G., Dumont, J., Gilliquet, V., Bolle, P.-A. \& Hilger, F. 
(1991). The YDp Plasmids: a uniform set of vectors bearing versatile gene disruption cassettes for Saccharomyces cerevisiae. Yeast 7, 475-477.

Blomberg, A. \& Adler, L. (1992). Physiology of osmotolerance in fungi. Adv Microb Physiol 33, 145-212.

Boy-Marcotte, E., Perrot, M., Bussereau, F., Boucherie, H. \& Jacquet, M. (1998). Msn2p and Msn4p control a large number of genes induced at the diauxic transition which are repressed by cyclic AMP in Saccharomyces cerevisiae. J Bacteriol 180, 1044-1052.

Brewster, J. L., de Valoir, T., Dwyer, N. D., Winter, E. \& Gustin, M. C. (1993). An osmosensing signal transduction pathway in yeast. Science 259, 1760-1763.

Brown, A. D. \& Edgley, M. (1980). Osmoregulation in yeast. In Symposium on Genetic Engineering of Osmoregulation, pp. 75-90. Edited by D. W. Rains, R. C. Valentine \& A. Hollander. New York: Plenum Press.

Cooper, J. P., Roth, S. Y. \& Simpson, R. T. (1994). The global transcriptional regulators, SSN6 and TUP1, play distinct roles in the establishment of a repressive chromatin structure. Genes Dev 8, 1400-1410.

Cyert, M. S. \& Thorner, J. (1992). Regulatory subunit (CNB1 gene product) of yeast $\mathrm{Ca}^{2+}$ /calmoduline dependent phosphoprotein phosphatases is required for adaptation to pheromone. Mol Cell Biol 12, 3460-3469.

Cyert, M. S., Kunisawa, R., Kaim, D. \& Thorner, J. (1991). Yeast has homologs (CNA1 and CNA2 gene products) of mammalian calcineurin, a calmodulin-regulated phosphoprotein phosphatase. Proc Natl Acad Sci USA 88, 7376-7380.

Danielsson, A., Larsson, C., Larsson, K., Gustafsson, G. \& Adler, L. (1996). A genetic analysis of the calcineurin and calmodulin in $\mathrm{Ca}^{2+}$-dependent improvement of $\mathrm{NaCl}$ tolerance of Saccharomyces cerevisiae. Curr Genet 30, 476-484.

Davenport, K. R., Sohaskey, M., Kamada, Y., Levin, D. E. \& Gustin, M. C. (1995). A second osmosensing signal transduction pathway in yeast - hypotonic shock activates the PKC1 protein kinase-regulated cell integrity pathway. J Biol Chem 270, 30157-30161.

Eberhardt, I. \& Hohmann, S. (1995). Strategy for deletion of complete open reading frames in Saccharomyces cerevisiae. Curr Genet 27, 306-308.

Eriksson, P., Andre, L., Ansell, R., Blomberg, A. \& Adler, L. (1995). Molecular cloning of GPD2, a second gene encoding sn-glycerol 3-phosphate dehydrogenase $\left(\mathrm{NAD}^{+}\right)$in Saccharomyces cerevisiae and its comparison to GPD1. Mol Microbiol 17, 95-107.

Gancedo, C., Gancedo, J. M. \& Sols, A. (1968). Glycerol metabolism in yeasts. Pathways of utilization and production. Eur $J$ Biochem 5, 165-172.

Görner, W., Durchschlag, E., Martinez-Pastor, M. T., Estruch, F., Ammerer, G., Hamilton, B., Ruis, H. \& Schüller, C. (1998). Nuclear localization of the $\mathrm{C} 2 \mathrm{H} 2$ zinc finger protein $\mathrm{Msn} 2 \mathrm{p}$ is regulated by stress and protein kinase A activity. Genes Dev 12, 586-597.

Guldener, U., Heck, S., Fiedler, T., Beinhauer, J. \& Hegemann, J. H. (1996). A new efficient gene disruption cassette for repeated use in budding yeast. Nucleic Acids Res 24, 2519-2524.

Hirata, D., Harada, S., Namba, H. \& Miyakawa, T. (1995). Adaptation to high-salt stress in Saccharomyces cerevisiae is regulated by $\mathrm{Ca}^{2+} /$ calmodulin-dependent phosphoprotein phosphatase (calcineurin) and cAMP-dependent protein kinase. $\mathrm{Mol}$ Gen Genet 249, 257-264.

Hirayama, T., Maeda, T., Saito, H. \& Shinozaki, K. (1995). Cloning and characterization of seven cDNAs for hyperosmolarity- responsive (HOR) genes of Saccharomyces cerevisiae. Mol Gen Genet 249, 127-138.

Hohmann, S. (1997). Shaping up: the response of yeast to osmotic stress. In Yeast Stress Responses, pp. 101-145. Edited by S. Hohmann \& W. H. Mager. Austin, TX: R. G. Landes.

Irie, K., Takase, M., Lee, K. S., Levin, D. E., Araki, H., Matsumoto, K. \& Oshima, Y. (1993). $M K K 1$ and $M K K 2$, which encode Saccharomyces cerevisiae mitogen-activated protein kinasekinase homologs, function in the pathway mediated by protein kinase C. Mol Cell Biol 13, 3076-3083.

Jacoby, T., Flanagan, H., Faykin, A., Seto, A. G., Mattison, C. \& Ota, I. (1997). Two protein tyrosine phosphatases inactivate the osmotic stress response pathway in yeast by targeting the mitogen activated protein kinase, Hog1. J Biol Chem 272, 17749-17755.

Keleher, C. A., Redd, M. J., Schultz, J., Carlson, M. \& Johnson, A. D. (1992). Ssn6-Tup1 is a general repressor of transcription in yeast. Cell 68, 709-719.

Kobayashi, N. \& McEntee, K. (1993). Identification of $c$ is and trans components of a novel heat shock stress regulatory pathway in Saccharomyces cerevisiae. Mol Cell Biol 13, 248-256.

Larsson, K., Eriksson, P., Ansell, R. \& Adler, L. (1993). A gene encoding $s n$-glycerol 3-phosphate dehydrogenase $\left(\mathrm{NAD}^{+}\right)$ complements an osmosensitive mutant of Saccharomyces cerevisiae. Mol Microbiol 10, 1101-1111.

Lee, K. S. \& Levin, D. E. (1992). Dominant mutations in a gene encoding a putative protein kinase ( $B C K 1)$ bypass the requirement for a Saccharomyces cerevisiae protein kinase $\mathrm{C}$ homolog. Mol Cell Biol 12, 172-182.

Lee, K. S., Irie, K., Gotoh, Y., Watanabe, Y., Araki, H., Nishida, E., Matsumoto, K. \& Levin, D. (1993). A yeast mitogen-activated protein kinase homolog $(\mathrm{Mpk} 1 \mathrm{p})$ mediates signalling by protein kinase C. Mol Cell Biol 13, 3067-3075.

Levin, D. E. \& Errede, B. (1995). The proliferation of MAP kinase signaling pathways in yeast. Curr Opin Cell Biol 7, 197-202.

Levin, D. E., Fields, F. O., Kunisawa, R., Bishop, J. M. \& Thorner, J. (1990). A candidate protein kinase C gene, $P K C 1$, is required for the $S$. cerevisiae cell cycle. Cell 62, 213-224.

Liu, Y., Ishii, S., Tokai, M., Tsutumi, H., Ohki, O., Akada, R., Tanaka, K., Tsuchiya, E., Fukui, S. \& Miyakawa, T. (1991). The Saccharomyces cerevisiae genes (CMP1 and CMP2) encoding calmodulin-binding proteins homologous to the catalytic subunit of mammalian protein phosphatase 2B. Mol Gen Genet 227, 52-59.

Maeda, T., Tsai, A. Y. M. \& Saito, H. (1993). Mutations in a protein tyrosine phosphatase gene (PTP2) and a protein serine/threonine phosphatase gene (PTC1) cause a synthetic growth defect in Saccharomyces cerevisiae. Mol Cell Biol 13, 5408-5417.

Maeda, T., Wurgler-Murphy, S. M. \& Saito, H. (1994). A twocomponent system that regulates an osmosensing MAP kinase cascade in yeast. Nature 369, 242-245.

Maeda, T., Takekawa, M. \& Saito, H. (1995). Activation of yeast PBS2 MAPKK by MAPKKKs or by binding of an SH3-containing osmosensor. Science 269, 554-558.

Mager, W. H. \& de Kruijff, A. J. J. (1995). Stress-induced transcription activation. Microbiol Rev 59, 506-531.

Marchler, G., Schüller, C., Adam, G. \& Ruis, H. (1993). A Saccharomyces cerevisiae UAS element controlled by protein kinase $A$ activates transcription in response to a variety of stress conditions. EMBO J 12, 1997-2003.

Márquez, J. A. \& Serrano, R. (1996). Multiple transduction pathways regulate the sodium-extrusion gene PMR2/ENA1 during salt stress in yeast. FEBS Lett 382, 89-92. 
Márquez, J. A., Pascual-Ahuir, A., Proft, M. \& Serrano, R. (1998). The $S$ sn6-Tup1 repressor complex of Saccharomyces cerevisiae is involved in the osmotic induction of HOG-dependent and -independent genes. EMBO J 17, 2543-2553.

Martin, H., Arroyo, J., Sanchez, M., Molina, M. \& Nombela, C. (1993). Activity of the yeast MAP kinase homologue Slt2 is critically required for cell integrity at $37^{\circ} \mathrm{C}$. Mol Gen Genet 241, 177-184.

Martinez-Pastor, M. T., Marchler, G., Schüller, C., Marchler-Bauer, A., Ruis, H. \& Estruch, F. (1996). The Saccharomyces cerevisiae zinc finger proteins $M s n 2 p$ and $M s n 4 p$ are required for transcriptional induction through the stress-response element (STRE). EMBO J 15, 2227-2235.

Mazon, M. J., Behrens, M. M., Morgado, E. \& Portillo, F. (1993). Low activity of the yeast cAMP-dependent protein kinase catalytic subunit Tpk3 is due to the poor expression of the TPK3 gene. Eur J Biochem 213, 501-506.

Mendoza, I., Rubio, F., Rodriguez-Navarro, A. \& Pardo, J. M. (1994). The protein phosphatase calcineurin is essential for $\mathrm{NaCl}$ tolerance of Saccharomyces cerevisiae. J Biol Chem 269, 8792-8796.

Mendoza, I., Quintero, F. J., Bressan, R. A., Hasegawa, P. M. \& Pardo, J. M. (1996). Activated calcineurin confers high tolerance to ion stress and alters the budding pattern and cell morphology of yeast cells. J Biol Chem 271, 23061-23067.

Nakamura, T., Liu, Y., Hirata, D., Namba, H., Harada, S.-I., Hirokawa, T. \& Miyakawa, T. (1993). Protein phosphatase type 2B (calcineurin)-mediated, FK506-sensitive regulation of intracellular ions in yeast is an important determinant for adaptation to high salt stress conditions. EMBO J 12, 4063-4071.

Nikawa, J., Cameron, S., Toda, T., Furguson, K. W. \& Wigler, M. (1987). Rigorous feedback control of cAMP levels in Saccharomyces cerevisiae. Genes Dev 1, 931-937.

Norbeck, J. \& Blomberg, A. (1997). Two-dimensional electrophoretic separation of yeast proteins using a non-linear wide range $(\mathrm{pH} 3-10)$ immobilized $\mathrm{pH}$ gradient in the first dimension; reproducibility and evidence for isoelectric focusing of alkaline ( $\mathrm{pI}>7$ ) proteins. Yeast 13, 1519-1534.

Norbeck, J., Păhlman, A. K., Akhtar, N., Blomberg, A. \& Adler, L. (1996). Purification and characterization of two isoenzymes of DLglycerol 3-phosphatase from Saccharomyces cerevisiae. Identification of the corresponding GPP1 and GPP 2 genes and evidence for osmotic regulation of Gpp2p expression by the osmosensing MAP kinase signal transduction pathway. J Biol Chem 271, 13875-13881.

Posas, F. \& Saito, H. (1997). Osmotic activation of the HOG MAPK pathway via Ste11p MAPKKK: scaffold role of Pbs2p MAPKK. Science 276, 1702-1705.

Posas, F. \& Saito, H. (1998). Activation of the yeast SSK2 MAP kinase kinase kinase by the SSK1 two-component response regulator. $E M B O J$ 17, 1385-1394.

Posas, F., Wurgler-Murphy, S. M., Maeda, T., Witten, E. A., Thai, T. C. \& Saito, H. (1996). Yeast HOG1 MAP kinase cascade is regulated by a multi-step phosphorelay mechanism in the SLN1YPD1-SSK1 'two-component' osmosensor. Cell 86, 865-875.

Prior, B. A. \& Hohmann, S. (1997). Glycerol production and osmoregulation. In Yeast Sugar Metabolism, pp. 313-337. Edited by F. K. Zimmermann \& K.-D. Entian. Lancaster: Technomic Publishing.

Roth, S. Y. (1995). Chromatin-mediated transcriptional repression in yeast. Curr Opin Genet Dev 5, 168-173.

Ruis, H. \& Schüller, C. (1995). Stress signaling in yeast. Bioessays 17, 959-965.

Schüller, G., Brewster, J. L., Alexander, M. R., Gustin, M. C. \& Ruis, H. (1994). The HOG pathway controls osmotic regulation of transcription via the stress response element (STRE) of the Saccharomyces cerevisiae CTT1 gene. EMBO J 13, 4382-4389.

Serrano, R. (1996). Salt tolerance in plant and microorganisms: toxicity targets and defense responses. Int Rev Cytol 165, 1-52.

Serrano, R., Márquez, J. A. \& Ríos, G. (1997). Crucial factors in salt tolerance. In Yeast Stress Responses, pp. 147-169. Edited by S. Hohmann \& W. H. Mager. Austin, TX: R. G. Landes.

Sherman, F., Fink, G. R. \& Hicks, J. B. (1983). Methods in Yeast Genetics. Cold Spring Harbor, NY: Cold Spring Harbor Laboratory.

Siderius, M. \& Mager, W. H. (1997). The general stress response in search for a common denominator. In Yeast Stress Responses, pp. 213-230. Edited by S. Hohmann \& W. H. Mager. Austin, TX: R. G. Landes.

Siderius, M., Rots, E. \& Mager, W. H. (1997). High-osmolarity signalling in Saccharomyces cerevisiae is modulated in a carbonsource-dependent fashion. Microbiology 143, 3241-3250.

Stark, M. J. R. (1996). Yeast protein serine/threonine phosphatases: multiple roles and diverse regulation. Yeast 12, 1647-1675.

Tamás, M. J., Luyten, K., Sutherland, F. C. W. \& 10 other authors (1999). Fps1p controls the accumulation and release of the compatible solute glycerol in yeast osmoregulation. Mol Microbiol (in press).

Thomas, B. J. \& Rothstein, R. J. (1989). Elevated recombination rates in transcriptionally active DNA. Cell 56, 619-630.

Toda, T., Uno, I., Ishikawa, T., Powers, S., Kataoka, T., Broek, D., Cameron, S., Broach, J., Matsumoto, K. \& Wigler, M. (1985). In yeast, $R A S$ proteins are controlling elements of adenylate cyclase. Cell 40, 27-36.

Varela, J. C. S., Praekelt, U. M., Meacock, P. A., Planta, R. J. \& Mager, W. H. (1995). The Saccharomyces cerevisiae HSP12 gene is activated by the high-osmolarity glycerol pathway and negatively regulated by protein kinase A. Mol Cell Biol 15, 6232-6245.

de Winde, J. H., Crauwels, M., Hohmann, S., Thevelein, J. M. \& Winderickx, J. (1996). Differential requirement of the yeast sugar kinases for sugar sensing in the establishment of the catabolite repressed state. Eur J Biochem 241, 633-643.

Wurgler-Murphy, S. M., Maeda, T., Witten, E. A. \& Saito, H. (1997). Regulation of the Saccharomyces cerevisiae Hog1 mitogen activated protein kinase by the Ptp2 and Ptp3 protein tyrosine phosphatases. Mol Cell Biol 17, 1289-1297.

Yancey, P. H., Clark, M. E., Hand, S. C., Bowlus, R. D. \& Somero, G. N. (1982). Living with water stress: evolution of osmolyte systems. Science 217, 1214-1222.

Received 25 September 1998; revised 16 November 1998; accepted 20 November 1998. 